Абуова Акбала Камидоллаевна, Докторант $\mathrm{PhD}$ Казахского университета путей сообщения г. Алматы, Казахстан

E-mail: akbala86@gmail.com ORCID ID: 0000-0002-8376-0501

\title{
АВТОМАТИЗИРОВАННЫЕ СИСТЕМЫ ПОДДЕРЖКИ РЕШЕНИЙ ПО РЕАГИРОВАНИЮ НА ЧРЕЗВЫЧАЙНЫЕ СИТУАЦИИ НА ЖЕЛЕЗНОДОРОЖНОМ ТРАНСПОРТЕ
}

\section{Abuova Akbala Kamidollaevna, $\mathrm{PhD}$ student The Kazakh University of Communications Almaty, the Republic of Kazakhstan E-mail: akbala86@gmail.com ORCID ID: 0000-0002-8376-0501}

\section{AUTOMATED SUPPORT SOLUTIONS FOR RESPONSE TO EMERGENCY SITUATIONS BY RAILWAY TRANSPORT}

\begin{abstract}
The emergency railway road situation is the result of the actions of a combination of a certain number of factors and conditions (technical, natural, etc.) that contribute to or counteract the implementation of measures by structural divisions of the functional subsystem to implement action plans.
\end{abstract}

Keywords: high-speed rail transport, situational center, emergency situations, automation.

Аннотация: Чрезвычайная железнодорожная дорога ситуация является следствием действий совокупности определенного количества факторов и условий (технических, естественных и т.д.), которые способствуют или противодействуют выполнению мероприятий структурными подразделениями функииональной подсистемы по реализации планов действий.

Ключевые слова: высокоскоростной железнодорожный транспорт, ситуачионный центр, чрезвычайные ситуации, автоматизация.

Подготовка, принятие и реализация управленческих решений по осуществлению организационно-технических мероприятий, направленных на обеспечение скоординированных действий структурных подразделений на чрезвычайные ситуации (ЧС) на железнодорожном (ж.-д.) транспорте (в том числе высокоскоростном) с целью ликвидации последствий ЧС в возможно короткие сроки, является главной задачей оперативных штабов.

Оперативные штабы предприятий «Казахстанские железные дороги» (КЖД), объединений, государственных предприятий, дирекций ж.-д. перевозок, учреждений организаций и структурных подразделений создаются для непосредственного руководства в пределах своей компетенции. Сейчас пункты управления высокоскоростным ж.-д. транспортом (ВСЖТ), по сути, являются соответствующими ситуационными центрами руководства реагированием на ЧС и представляют собой иерархическую систему, отражающую структуру управления ВСЖТ.

\footnotetext{
Чрезвычайные ситуации на железнодорожном транспорте
}

Материалы Международной практической интернет-конференции «Актуальные Проблемы Науки» 
Высшим пунктом (первым уровнем) управления является центр управления КЖД (потенциально - это будущий главный ситуационный центр (СЦ)). Второй уровень управления процессами реагирования на ЧС составляют существующие пункты диспетчерского управления региональных филиалов железных дорог. К третьему уровню управления относятся пункты управления дирекций железных дорог, которые непосредственно руководят подразделениями железнодорожного транспорта, входящих в состав функциональной подсистемы реагирования на чрезвычайные ситуации (исполнители). На всех пунктах управления в случае ЧС создаются оперативные штабы.

В публикациях $[1,2]$ было показано, что опасные ж.-д. ЧС, вызванные транспортными происшествиями, характеризуются резким кратковременным изменением параметров внутренних и внешних процессов развития таких ситуаций и состояний элементов транспортной системы. Они могут привести к негативному воздействию на подвижной состав, грузы, объекты инфраструктуры железной дороги, гибели (травмированию) людей, значительным материальным потерям и ущербу окружающей среде.

Чрезвычайная ж.-д. ситуация является следствием действий совокупности определенного количества факторов и условий (технических, естественных и т.д.), которые способствуют или противодействуют выполнению мероприятий структурными подразделениями функциональной подсистемы по реализации планов действий. Эти планы действий специальных подразделений уточняются в условиях конкретного вида и уровня ЧС для оказания неотложной помощи пострадавшим, защиты персонала, сокращения материальных затрат и ущерба окружающей среде и восстановления нормального функционирования железнодорожного транспорта.

Действия разнородных по назначению подразделений функциональной подсистемы ж.-д. транспорта по локализации опасных ситуаций и ликвидации их последствий определяются значительной сложностью, которая обусловлена влиянием разнохарактерных опасных факторов таких ситуаций на людей, технику и окружающей среды, а также сложностью организации управления этими подразделениями в сложных условиях их работы. Решение таких задач невозможно без широкого применения компьютеризированных систем, в том числе экспертных и систем поддержки принятия решений.

Для автоматизации оценки обстановки, сложившейся в результате возникновения и развития ЧС, необходимо иметь большое количество информации о характере развития ЧС во времени и пространстве, состоянии специальных подразделений и результатов их действий, обеспеченности материально-техническими средствами, средствами индивидуальной защиты и т.д., причем это количество информации непрерывно растет вместе с развитием ситуации. Для минимизации последствий ЧС в условиях стремительного роста информационных потоков и дефицита времени встает необходимость в создании четко выстроенной системы автоматизированного оперативного информационно-аналитического обеспечения анализа обстановки, выработки и принятия решений по управлению реагированием на ЧС с широким применением современной вычислительной техники, информационных технологий и систем поддержки принятия решений. Сейчас в практику управления сложными динамическими многозвенными системами вошли управленческие системы типа СЦ.

При этом под центром понимается не только специально оборудованное помещение, но и соответствующие информационные, телекоммуникационные,

\footnotetext{
Чрезвычайные ситуации на железнодорожном транспорте
}

Материалы Международной практической интернет-конференции «Актуальные Проблемы Науки» 
программные и методические средства, обеспечивающие процесс доставки агрегации информации с целью выработки соответствующего решения.

Все вышесказанное предполагает разработку моделей и методов построения систем поддержки принятия решений по реагированию на чрезвычайные ситуации на железнодорожном транспорте (в том числе высокоскоростном), что является предметом наших дальнейших исследований.

\section{ЛИТЕРАТУРА}

1. Gorry G.A. A Framework for Management Information Systems / G.A. Gorry, M.S. Scott Morton // Sloan Management Review. - 1971. - 13, № 1. - P. 55-70.

2. Tseng, Y. Y., Yue, W. L., \& Taylor, M. A. (2018). The role of transportation in logistics chain. Eastern Asia Society for Transportation Studies. 